\title{
Simulação in vitro de condições de uso de desinfetantes e avaliação da eficácia frente bactérias sobreviventes a higienização de superfícies em matadouro-frigorífico de bovinos
}

\author{
In vitro simulations of use conditions of disinfectants and evaluation \\ of its efficacy on survivors bacteria to surfaces hygienization \\ in bovine slaughterhouse
}

Paulo Duran dos Santos Molina, ${ }^{*}$ Liris Kindlein, ${ }^{* *}$ Guiomar Pedro Bergmann, ${ }^{* *}$ César Augusto Marchionatti Avancini ${ }^{\star \star * *}$

\begin{abstract}
Resumo
$\mathrm{Na}$ indústria da carne, a desinfecção das superfícies de contato com o alimento é importante barreira sanitária para evitar que micro-organismos deteriorantes e patogênicos degradem o alimento ou ponham em risco a saúde dos consumidores. Para simular in vitro condições de uso, pelo teste de suspensão, os desinfetantes quaternário de amônio, ácido peracético, clorhexidina, iodofor e hipoclorito de sódio foram confrontados com Staphylococcus aureus, Escherichia coli e dois pools de bactérias, todos organismos sobreviventes à higienização de um matadouro-frigorífico de bovinos. 0 delineamento do experimento: 5 concentrações dos desinfetantes; sem e com matéria orgânica; tempos de contato 5, 10, 15 e 20 minutos. Como resultados, as menores concentrações e os menores tempos de contato para inativação de todas as bactérias foram: quaternário de amônio $25 \mathrm{ppm} / 20 \mathrm{~min}$ ou $50 \mathrm{ppm} / 5 \mathrm{~min}$; ácido peracético $6,25 \mathrm{ppm} / 10 \mathrm{~min}$ ou $25 \mathrm{ppm} / 5 \mathrm{~min}$; clorhexidina $12,5 \mathrm{ppm} / 15 \mathrm{~min}$ ou $200 \mathrm{ppm} / 5 \mathrm{~min}$; iodofor $50 \mathrm{ppm} / 5 \mathrm{~min}$ e hipoclorito de sódio $200 \mathrm{ppm} / 5 \mathrm{~min}$. Concluiu-se que todos os desinfetantes podem ser usados para inativar as bactérias isoladas, porém a simulação in vitro evidenciou que equívocos na operacionalização permitem a sobrevivência dos micro-organismos no ambiente.
\end{abstract}

Palavras-chave: desinfecção, desinfetantes, higiene.

\begin{abstract}
In the meat-processing industry, the efficient disinfection of meat contact surfaces is an important sanitary barrier to avoid deteriorating and potentially pathogenic microorganisms degrading the meat or pose a health hazard to consumers. Aiming simulate in vitro use conditions, through suspension test, the disinfectants ammonium quaternary, peracetic acid, chlorhexidine, iodophor and sodium hipochlorite were confronted with Staphylococcus aureus, Escherichia coli and two bacterial pools, all surviving organisms to hygienization in a bovine slaughterhouse with high slaughtering capability. The recherach was designed wch the factors: 5 disinfectants concentrations, without and wth organic matter (sterile bovine serum), contact times of 5, 10, 15 and 20 minutes. Through this investigative line and the aforementioned indicator organisms, the lesser concentration and the lesser contact time to inactivate all bacterial culture were: ammonium quaternary $25 \mathrm{ppm} / 20 \mathrm{~min}$ or $50 \mathrm{ppm} / 5 \mathrm{~min}$; peracetic acid 6,25 ppm/10 min or $25 \mathrm{ppm} / 5 \mathrm{~min}$; chlorhexidine $12,5 \mathrm{ppm} / 15 \mathrm{~min}$ or $200 \mathrm{ppm} / 5 \mathrm{~min}$; iodophor $50 \mathrm{ppm} / 5 \mathrm{~min}$ and sodium hipochlorite $200 \mathrm{ppm} / 5 \mathrm{~min}$. All evaluated disinfectants can be utilized to inactivate surviving bacterial cultures in the slaughterhouse. On the other hand, the simulation indicates that the in loco manipulation of factors concentration, contact time and organic matter, besides others, can allow the microorganisms survival in the medium.
\end{abstract}

Keywords: disinfection, disinfectants, sanitation.

\section{Introdução}

Em matadouro-frigorífico, as superfícies e equipamentos de manipulação das carnes podem servir como fonte de infecção tanto por micro-organismos potencialmente patogênicos para os seres humanos, quanto por microorganismos deteriorantes. Entre os procedimentos adotados na prevenção dessa contaminação, está prevista a higienização da instalação. Por higienização (Brasil, 2002) compreende-se a operação que se divide em duas etapas:

\footnotetext{
* Programa de Pós-Graduação em Ciências Veterinárias (Mestrado) - Universidade Federal do Rio Grande do Sul.

** Centro de Ensino, Pesquisa e Tecnologia em Carnes e Derivados (CEPETEC) - Faculdade de Veterinária - Universidade Federal do Rio Grande do Sul.

*** Departamento de Medicina Veterinária Preventiva - Programa de Pós-Graduação em Ciências Veterinárias - Faculdade de Veterinária Universidade Federal do Rio Grande do Sul, Av. Bento Gonçalves no. 9.090, Bairro Agronomia, Porto Alegre - RS/BR. CEP 91540-000.

A quem enviar correspondência: cesar.avancini@ufrgs.br.
} 
limpeza, para a remoção de resíduos e desinfecção, para agir sobre os micro-organismos remanescentes.

No entanto, pesquisas demonstram que diversos microorganismos sobrevivem a este procedimento nas mesas e equipamentos de matadouros (Macedo e Sand, 2005; Menezes et al., 2007). Esse fato pode ser atribuído a possíveis deficiências na higienização, ou à resistência intrínseca dos micro-organismos. Por exemplo, Sundhein et al. (1998) relatam sobre micro-organismos que apresentaram diferentes graus de resistência frente ao quaternário de amônio. Também, a experiência com o uso de antibióticos e biocidas de ambiente indica (Russel, 1998) que não há agente químico que não possa, eventualmente, selecionar ou induzir resistência nos micro-organismos.

Visando monitorar a desinfecção como barreira sanitária na prevenção de enfermidades transmitidas por alimentos, bem como no controle de bactérias deteriorantes, para esse trabalho, teve-se como objetivo simular in vitro condições de uso na avaliação da eficácia da atividade antimicrobiana que os desinfetantes quaternário de amônio, ácido peracético, clorhexidina, iodofor e hipoclorito de sódio apresentam sobre bactérias sobreviventes à higienização de um matadourofrigorífico de bovinos.

\section{Material e métodos}

\section{Micro-organismos}

Em um matadouro-frigorífico com abate médio de 600 bovinos/dia e com Programa de Análise de Perigos e Pontos Críticos de Controle implantado, nos primeiros meses de 2008, após os procedimentos de higienização e momentos antes do início do abate e desossa, com swabs foram realizadas três coletas em 25 diferentes superfícies de manipulação e de equipamentos que entravam em contato direto com as carnes.

Na pesquisa e isolamento de Staphylococcus aureus utilizouse 0 meio seletivo ágar Baird-Parker (Merk®). Na de Escherichia coli foi realizada semeadura direta em placas com meio seletivo E. coli Cromogênico (Laborclin $\AA$ ). A identificação de $S$. aureus foi confirmada pelas provas de coagulase em tubo, teste da catalase, meio de cultivo Clarks Lubs (VM/VP - vermelho de metila e Vogues Proskauer), caldo ONPG (beta galactosidadse) e teste de fermentação de manitol. A de E. coli pela semeadura em meio Mc Conkey, oxidase, meio TSI (triple sugar iron), meio VM/VP, citrato e meio de cultivo SIM. Após a identificação, uma colônia de cada espécie foi armazenada em ágar-nutriente.

Também foram formados dois pools de bactérias sobreviventes, provenientes dos meios seletivos acima informados. Para formar os pools foram retiradas colônias de cada uma das três coletas, totalizando seis colônias provenientes do meio seletivo para $S$. aureus ( $P o o l \mathrm{BP})$ e seis colônias do meio seletivo para $E$. coli (Pool EC), todas não caracterizáveis como sendo destes gêneros e espécies. As colônias foram semeadas juntas em caldo BHI, conforme o respectivo pool, incubadas a $37^{\circ} \mathrm{C}$ por 24 horas e armazenadas em ágar-nutriente.

Para o experimento, a dose infectante das "culturas-teste" foi ajustada entre $10^{7}$ e $10^{5} \mathrm{UFC} / \mathrm{mL}$.

\section{Desinfetantes}

Foram testadas cinco soluções desinfetantes, apropriadas para uso em ambientes de manipulação de alimentos (Brasil, 2007). Todos os compostos químicos desinfetantes possuíam laudo técnico de pureza e foram diluídos em graus geométricos com fator 0,5 de modo a formar cinco concentrações de cada um. O quaternário de amônio (cloreto de benzalcônio - Delaware $\AA$ ), a clorhexidina (digluconato de clorhexidina - Delaware®) e o hipoclorito de sódio (Cromoline $\AA$ ) foram usados nas concentrações de 200 ppm, 100 ppm, 50 ppm, 25 ppm e 12,5 ppm. Já o ácido peracético (Cromoline ${ }^{\circledR}$ ) e o iodofor (Top Glass ${ }^{\circledR}$ ) nas de 100 ppm, 50 ppm, 25 ppm, 12,5 ppm e 6,25 ppm.

Teste de eficácia antimicrobiana

A avaliação da atividade antimicrobiana, simulando condições de uso, foi realizada pelo método de diluição, com teste de suspensão (Brasil, 1993), tendo como delineamento os fatores (condições de uso) concentrações do desinfetante, sem e com matéria orgânica e tempos de contato 5, 10,15 e 20 minutos, quando através de alça de platina calibrada em $10 \mathrm{~mL}$ uma alíquota era repicada para tubos de ensaio com $1 \mathrm{~mL}$ de BHI (tubo de verificação da atividade do desinfetante, neutralizado por 100 vezes diluído). A adição de $1 \%$ de matéria orgânica (soro bovino estéril- Sorali®) teve o objetivo de simular deficiência de limpeza das superfícies.

A leitura dos tubos de verificação da atividade do desinfetante foi realizada a cada 24 horas, sendo definido o resultado nas 96 horas. Considerou-se que o desinfetante inativou (eficaz) os inóculos quando o meio de cultura dos tubos de verificação não apresentava turbidez, e que não inativou (ineficaz) quando o meio de cultura dos tubos apresentava turbidez. Para todos os tubos que apresentaram turbidez, realizou-se a confirmação da pureza das culturas-teste ativas através da semeadura em meio seletivo.

\section{Análise estatística}

Frente a cada isolado ou pool bacteriano os resultados da confrontação dos desinfetantes foram verificados de modo descritivo, conforme eficácia de inativação segundo os fatores/variáveis delineados. Já frente ao conjunto de todas as bactérias, tendo os resultados de inativação pelos desinfetantes na ausência de matéria orgânica apresentadose estatisticamente sem variabilidade, na presença de matéria orgânica os resultado foram submetidos à análise da variância (distribuição binomial para variável resposta e teste Ismeans), tendo como variáveis independentes os fatores concentração e tempo de contato).

\section{Resultados e discussão}

Nas Tabelas 1 e 2 são apresentados, de modo descritivo, os resultados das menores concentrações dos desinfetantes e os menores tempos de contato necessários para inativar as bactérias.

Quando o fator menor concentração não coincidiu com o fator menor tempo de contato para a inativação, nessas Tabelas aparecem duas anotações, cada uma correspondendo ao melhor resultado de eficácia, segundo um dos fatores. 
Tabela 1: Menores concentrações e tempos de contato para inativar bactérias isoladas de superfícies e equipamentos de um matadouro-frigorífico, resultados obtidos pelo teste de suspensão na ausência de matéria orgânica

\begin{tabular}{|c|c|c|c|c|c|c|c|c|}
\hline \multirow[b]{2}{*}{ QA } & \multirow[b]{2}{*}{$\begin{array}{l}\mathrm{C} \\
\mathrm{TC}\end{array}$} & \multicolumn{2}{|c|}{ S. aureus } & \multicolumn{2}{|c|}{ E. coli } & \multirow{2}{*}{$\begin{array}{c}\begin{array}{c}\text { Pool } \\
B P\end{array} \\
\begin{array}{c}12,5 \\
5\end{array}\end{array}$} & \multicolumn{2}{|c|}{$\begin{array}{c}\text { Pool } \\
E C\end{array}$} \\
\hline & & 12 & & $\begin{array}{c}12,5 \\
15\end{array}$ & $\begin{array}{c}25 \\
5\end{array}$ & & $\begin{array}{c}12,5 \\
10\end{array}$ & $\begin{array}{c}25 \\
5\end{array}$ \\
\hline ÁP & $\begin{array}{l}\mathrm{C} \\
\mathrm{TC}\end{array}$ & $\begin{array}{c}6,25 \\
10\end{array}$ & $\begin{array}{c}25 \\
5\end{array}$ & \multicolumn{2}{|c|}{$\begin{array}{c}6,25 \\
5\end{array}$} & $\begin{array}{c}6,25 \\
5\end{array}$ & \multicolumn{2}{|c|}{$\begin{array}{c}6,25 \\
5\end{array}$} \\
\hline $\mathrm{Cl}$ & $\begin{array}{l}\mathrm{C} \\
\mathrm{TC}\end{array}$ & \multicolumn{2}{|c|}{$\begin{array}{c}12,5 \\
5\end{array}$} & $\begin{array}{c}12,5 \\
10\end{array}$ & $\begin{array}{c}25 \\
5\end{array}$ & $\begin{array}{c}12,5 \\
5\end{array}$ & \multicolumn{2}{|c|}{12,5} \\
\hline I & $\begin{array}{l}\mathrm{C} \\
\mathrm{TC}\end{array}$ & \multicolumn{2}{|c|}{$\begin{array}{c}6,25 \\
5\end{array}$} & \multicolumn{2}{|c|}{$\begin{array}{c}6,25 \\
5\end{array}$} & $\begin{array}{c}6,25 \\
5\end{array}$ & \multicolumn{2}{|c|}{$\begin{array}{c}6,25 \\
5\end{array}$} \\
\hline $\mathrm{H}$ & $\begin{array}{l}\mathrm{C} \\
\mathrm{TC}\end{array}$ & $\begin{array}{c}12,5 \\
10\end{array}$ & $\begin{array}{c}25 \\
5\end{array}$ & \multicolumn{2}{|c|}{12,5} & $\begin{array}{c}12,5 \\
5\end{array}$ & \multicolumn{2}{|c|}{12,5} \\
\hline
\end{tabular}

Pool BP: pool de bactérias do meio Baird Parker; Pool EC: pool de bactérias do meio monitoramento cromogênico; $Q A$ : quaternário de amônio; AP: ácido peracético; Cl: clorhexidina; I: iodofor; H: hipoclorito de sódio; C: concentração mínima de inativação (ppm); TC: tempo de contato para inativação (min.).

Tabela 2: Menores concentrações e tempos de contato para inativar bactérias isoladas de superfícies e equipamentos de um matadouro-frigorífico, resultados obtidos pelo teste de suspensão na presença de matéria orgânica

\begin{tabular}{|c|c|c|c|c|c|c|c|c|}
\hline \multirow[b]{2}{*}{ QA } & \multirow[b]{2}{*}{$\begin{array}{l}\mathrm{C} \\
\mathrm{TC}\end{array}$} & \multicolumn{2}{|c|}{ S. aureus } & \multicolumn{2}{|c|}{ E. coli } & \multirow{2}{*}{$\begin{array}{c}\begin{array}{c}\text { Pool } \\
B P\end{array} \\
\begin{array}{c}12,5 \\
5\end{array}\end{array}$} & \multicolumn{2}{|c|}{$\begin{array}{c}\text { Pool } \\
\text { EC }\end{array}$} \\
\hline & & $\begin{array}{c}12,5 \\
15\end{array}$ & $\begin{array}{c}25 \\
5\end{array}$ & $\begin{array}{c}12,5 \\
20\end{array}$ & $\begin{array}{c}25 \\
5\end{array}$ & & $\begin{array}{l}25 \\
20\end{array}$ & $\begin{array}{c}50 \\
5\end{array}$ \\
\hline ÁP & $\begin{array}{l}\mathrm{C} \\
\mathrm{TC}\end{array}$ & $\begin{array}{c}6,25 \\
10\end{array}$ & $\begin{array}{c}25 \\
5\end{array}$ & $\begin{array}{c}6,25 \\
10\end{array}$ & $\begin{array}{c}12,5 \\
5\end{array}$ & $\begin{array}{c}6,25 \\
5\end{array}$ & \multicolumn{2}{|c|}{$\begin{array}{c}6,25 \\
5\end{array}$} \\
\hline $\mathrm{Cl}$ & $\begin{array}{l}\mathrm{C} \\
\mathrm{TC}\end{array}$ & $\begin{array}{c}12,5 \\
10\end{array}$ & $\begin{array}{c}25 \\
5\end{array}$ & $\begin{array}{c}12,5 \\
15\end{array}$ & $\begin{array}{c}200 \\
5\end{array}$ & $\begin{array}{c}12,5 \\
5\end{array}$ & $\begin{array}{c}12,5 \\
10\end{array}$ & $\begin{array}{c}25 \\
5\end{array}$ \\
\hline I & $\begin{array}{l}\mathrm{C} \\
\mathrm{TC}\end{array}$ & \multicolumn{2}{|c|}{$\begin{array}{c}50 \\
5\end{array}$} & \multicolumn{2}{|c|}{$\begin{array}{c}50 \\
5\end{array}$} & $\begin{array}{c}50 \\
5\end{array}$ & \multicolumn{2}{|c|}{$\begin{array}{c}50 \\
5\end{array}$} \\
\hline $\mathrm{H}$ & $\begin{array}{l}\mathrm{C} \\
\mathrm{TC}\end{array}$ & \multicolumn{2}{|c|}{$\begin{array}{c}100 \\
5\end{array}$} & $\begin{array}{l}50 \\
20\end{array}$ & $\begin{array}{c}100 \\
5\end{array}$ & $\begin{array}{l}50 \\
20\end{array}$ & $\begin{array}{c}200 \\
5\end{array}$ & $\begin{array}{c}200 \\
5\end{array}$ \\
\hline
\end{tabular}

Pool BP: pool de bactérias do meio Baird Parker; Pool EC: pool de bactérias do meio monitoramento cromogênico; QA: quaternário de amônio; ÁP: ácido peracético; Cl: clorhexidina; I: iodofor; H: hipoclorito de sódio; C: concentração mínima de inativação (ppm); TC: tempo de contato para inativação (min.).

Se nas Tabelas 1 e 2 o critério de indicação de eficácia de inativação do desinfetante referiu-se a um inóculo identificado e a um pool de bactérias, na Tabela 3 foi informado quais as menores concentrações e tempos de contato dos desinfetantes que, estatisticamente significativo, foram capazes de inativar o conjunto de todas as bactérias presentes e isoladas nas superfícies do matadouro- frigorífico, independentemente de gênero ou isolamento por meio seletivo. Do ponto de vista prático, para o sanitarista/ higienista, essa parece ser a mais útil informação de referência para o procedimento desinfecção do ambiente. $\mathrm{Na}$ Tabela 3 também pode ser observado que não existe informação quanto à indicação de concentração de inativação do hipoclorito de sódio. Entretanto, observando a Tabela 2, pode-se verificar que a concentração de 200 ppm desse desinfetante foi a mais baixa que inativou os microorganismos isolados e confrontados. No entanto, a análise estatística definiu não haver diferença significativa entre as concentrações que inativaram e as que não inativaram as bactérias. Assim, seguindo o cunho prático proposto para esse desinfetante, sugere-se adotar o resultado apresentado na Tabela 2, mas alertar sobre a ausência de diferença matemática entre os resultados eficaz/ineficaz para esse antimicrobiano.

Tabela 3: Menores concentrações dos desinfetantes e menores tempos de contato que, estatisticamente significativo, foram necessários para inativar, usando o teste de suspensão simulando condições de uso na presença de matéria orgânica, o conjunto de todas as bactérias isoladas nas superfícies e equipamentos de um matadouro-frigorífico

\begin{tabular}{llccccc}
\hline & & QA & ÁP & Cl & I & H \\
\hline Fator & C & 25 & 6,25 & 12,5 & 50 & - \\
concentração & TC & 20 & 10 & 15 & 5 & - \\
Fator & TC & 5 & 5 & 5 & 5 & - \\
tempo de contato & C & 50 & 25 & 200 & 50 & -
\end{tabular}

QA: quaternário de amônio; ÁP: ácido peracético; Cl: clorhexidina; I: iodofor; $\mathrm{H}$ : hipoclorito de sódio; $\mathrm{C}$ : concentração de inativação (ppm); TC: tempo de contato para inativação ( $\mathrm{min})$; -: sem diferença estatística entre as interações (pd"0,05).

Existem dificuldades para definir exatamente onde a variação natural de tolerância ao desinfetante termina, e a resistência microbiana começa. Outro problema também é distinguir a verdadeira resistência da pseudorresistência, a qual é causada principalmente por erros na aplicação dos desinfetantes (Heinzel, 1998). Nessa pesquisa que desenvolvemos não foram usados instrumentos para avaliar a resistência das bactérias, e sim a atividade dos desinfetantes sobre esses micro-organismos. O que significa, baseado na referência acima informada, verificar possíveis pseudorresistências ou até variações naturais de tolerância dos micro-organismos. Com esse foco, abaixo interpretam-se os resultados e suas variações influenciadas pelos fatores que interferiram na inatiavação dos isolados. Depois, comparam-se os resultados com os apresentados por outras investigações.

Observou-se que todos os desinfetantes inativaram as bactérias isoladas nas superfícies do matadouro. Quando os desinfentantes agiram sobre os isolados na ausência de matéria orgânica, todos inativaram todas as bactérias sempre na menor concentração usada. Mas apenas o lodofor o fez sempre na menor concentração e também no menor tempo de contato. Interessante apontar que esse era, à época, 
o princípio ativo de rotina usado nas superfícies do matadouro onde as bactérias foram isoladas.

Quando a condição de confrontação desinfetante vs bactérias ocorreu na presença de matéria orgânica, apenas o ácido peracético e a clorhexidina inativaram todos os inóculos sempre na menor concentração, mas nunca sobre todos os micro-organismos na menor concentração e menor tempo de contato, concomitantemente.

Quanto aos tempos de leitura de 24, 48, 72 e 96 horas, dos 2.400 tubos de verificação da atividade dos desinfetantes, somente em 6 observou-se a ação de bacteriostasia. E exclusivamente nas primeiras 24 horas, mas tendo na leitura das 48 horas os inóculos apresentado crescimento. Esse fenômeno foi observado unicamente para os desinfetantes ácido perácetico (1 tubo) e hipoclorito de sódio (5 tubos), na presença de matéria orgânica. O achado confirma a necessidade de realizar leituras até o tempo de 96 horas, para evitar os resultados falsos negativos.

Para inativar os micro-organismos na presença de matéria orgânica os desinfetantes iodofor e hipoclorito de sódio necessitaram maior concentração que os demais testados. Outros estudos (Gélinas e Goulet, 1983; Both et al., 2009) também concluíram que esses dois grupos químicos têm menor atividade antimicrobiana na presença de matéria orgânica. A explicação mais aceita para esse fenômeno, no que se refere ao cloro [mas que se aplica também ao iodofor (Bessens, 1998)] é a de que na presença de matéria orgânica o cloro livre é rapidamente transformado em formas de cloro combinado, o que resulta em pequena inativação de microorganismos (Souza e Daniel, 2005), além do efeito protetor da matéria particulada (Holf e Akin, 1986).

Alguns autores avaliam que, ainda quanto à presença de matéria orgânica, alguns desinfetantes sofrem menos influência deste fator. A clorhexidina mantém sua ação desinfetante mesmo na presença de resíduos orgânicos (Gélinas e Goulet, 1983), fenômeno similar ao que ocorreria

\section{Conclusão}

Concluiu-se que todos os desinfetantes avaliados podem ser usados para inativar as bactérias isoladas. No entanto,

\section{Referências}

AARESTRUP F.M.; HASMAN H. Susceptibility of different bacterial species isolated from food animals to copper sulphate, zinc chloride and antimicrobial substances used for disinfection. Veterinary Microbiology, v. 100, p. 83-89, 2004.

BAMBACE A.M.J., BARROS E.J.A., SANTOS S.S.F.; JORGE A.O.C.. Eficácia de soluções aquosas de clorexidina para desinfecção de superfícies. Revista Biociências, v. 9, p. 73-81, 2003.

BESSEMS E. The effect of practical conditions on the efficacy of disinfectants. International Biodeterioration \& Biodegradation, v. 41, p. 177-183, 1998.

BOTH J.M.C., LONGARAY, S.M., AVANCINI, C.A.M. O desinfetante hipoclorito de sódio como barreira sanitária: condições de atividade frente a Staphylococcus aureus isolados em alimentos envolvidos em surtos de toxinfecções alimentares. Revista do Instituto Adolfo Lutz, v. 68, n. 2, p. 88-92, 2009. com o quaternário de amônio e o ácido peracético (Holah, et al., 1990; Souza e Daniel, 2005; Kasková et al., 2007). Os resultados obtidos nesse trabalho, cotejando a Tabela $1 \mathrm{com}$ a Tabela 2, vêm ao encontro dos resultados dos trabalhos supracitados. Em tempo, observar que frente à E.coli a concentração de clorhexidina para inativar esse inóculo na presença de matéria orgânica foi muito superior à necessária para inativá-lo no mesmo tempo de contato na ausência do soro bovino.

Verificou-se que a eficácia do ácido peracético sobre S. aureus e $E$. coli é similar tanto na ausência quanto na presença de matéria orgânica, promovendo a inativação em baixas concentrações e pouco tempo de contato, resultados que coincidem com os verificados por Souza e Daniel (2005) e Kasková et al., (2007). Porém, há relatos divergentes, como o de López et al., (2002), indicando que o ácido peracético pode ser mais eficaz contra micro-organismos Gram positivos, e o de Kunigk e Almeida (2001) informando que o $S$. aureus é mais resistente para este desinfetante que $E$. coli.

Os resultados estatísticos também evidenciaram que pode haver risco sanitário quando se ancora a escolha da concentração e do tempo de contato mais eficazes de uso dos desinfetantes, se os testes de avaliação da eficáica dos antimicrobianos de ambiente têm como indicadores biológicos de atividade apenas um ou dois gêneros bacterianos. Essa afirmação pode ser confirmada observando-se na Tabela 3 as indicações significativamente mais eficazes de uso dos desinfetantes, e conferindo ou comparando na Tabela 2 as concentrações e tempos de contato necessários para inativação dos diferentes isolados. Percebe-se que a indicação de uso mais eficaz do quaternário de amônio foi devido à maior dificuldade em inativar o pool E. coli (EC). Já para o ácido peracético, o $S$. aureus necessitou de maior concentração para melhorar a performance de tempo de contato. A clorhexidina teve maior dificuldade de inativar a $E$. coli e, para o iodofor, não foi encontrada diferença na eficácia frente aos indicadores biológicos.

os testes de simulação in vitro de fatores que interferem na sua eficácia em uso, forneceram evidências de que equívocos na operacionalização permitem a sobrevivência dos micro-organismos no ambiente.

BRASIL - Portaria n 101, de 17 de agosto de 1993. Ministério da Agricultura, Pecuária e Abastecimento. Métodos de Análise Microbiológica para Alimentos. Diário Oficial[da] República Federativa do Brasil, Brasília, DF, 17 de agosto de 1993, Seção 1, p. 1193711945.

BRASIL-Ministério da Saúde. Agência Nacional de Vigilância Sanitária (ANVISA). Resolução RDC n. 275, de 21 de outubro de 2002. Disponível em: <http://www.anvisa.gov.br/e-legis>. Acesso em: 22/ 01/2009.

BRASIL-Ministério da Saúde. Agência Nacional de Vigilância Sanitária (ANVISA). Resolução RDC n. 14, de 28 de fevereiro de 2007. Disponível em: <http://www.anvisa.gov.br/e-legis>. Acesso em: 15/ 07/2007.

GÉLINAS P.; GOULET J. Neutralization of the activity of eight disinfectants by organic matter. Journal of Applied Bacteriology, v. 54, p. 243-247, 1983. 
HOFF J.C.; AKIN E.W. Microbial resistance to disinfectants: mechanisms and significance. Environmental Health Perspectives, v. 69 , p. $7-13,1986$.

HOLAHJ.T., HIGGSC., ROBINSONS., WORTHINGTOND.; SPENCELEY $\mathrm{H}$. A conductance-based surface disinfection test for food hygiene. Letters in Applied Microbiology, v. 11, p. 255-259, 1990.

HEIZEL, M. Phenomena of biocide resistance in microorganisms. International Biodeterioration \& Biodegradation, v. 41, p. 225-234, 1998.

KASKOVÁ A., ONDRASOVICOVÁ O., VARGOVÁ M., ONDRASOVIC M.; VENGLOVSKÝ J. Application of peracetic acid and quaternary ammonium disinfectants as a part of sanitary treatment in a poultry house and poultry processing plant. Zoonoses and Public Health, v. 54, p. 125-130, 2007.

KUNIGK L.; ALMEIDA M.C.B. Action of peracetic acid on Escherichia coliand Staphylococcus aureus in suspension or settled on stainless steel surfaces. Brazilian Journal of Microbiology, v. 32, p. 38-41, 2001.

LÓPEZ L.V., ROMERO J.R.; URETA F.V. Acción germicida in vitro de productos desinfetantes de uso en la industria de alimentos. Archivos Latinoamericanos de Nutricion, v. 52, p. 74-76, 2002.
MACEDO N.T.S.; SAND S.T.V.D. Characterization of microorganisms present in a slaughterhouse and beef processing/chilling environment. Acta Scientiae Veterinariae, v. 33, p. 139-146, 2005.

MENEZES L.F., ALVES G.M.C., MELLO C.A. \& GARCIAJ.C.J. Avaliação das condições higiênico-sanitárias de superfícies de equipamentos, em matadouro-frigorífico de bovinos no município de Várzea Grande, MT. Higiene Alimentar, v. 21, p. 80-84, 2007.

RUSSEL, A.D. Bacterial resistance to disinfectants: present knowledge and future problems. Journal of Hospital Infection, v. 43 (suplement), p. S57 - S68, 1998.

SOUZA J.B.; DANIEL L.A.. Comparação entre hipoclorito de sódio e ácido peracético na inativação de $\mathrm{E}$. coli, colifagos e $\mathrm{C}$. perfringens em água com elevada concentração de matéria orgânica, Engenharia Sanitária e Ambiental, v. 10, p. 111-117, 2005.

SUNDHEIN G., LANGSRUDS., HEIRE.; HOLCKA.L. Bacterial resistance to disinfectants containing quaternary ammonium compounds. International Biodeterioration \& Biodegradation, v. 41, p. 235-239, 1998. 